\title{
Effectiveness of mometasone furoate nasal spray on tympanometric results and hearing loss in children with otitis media with effusion
}

\author{
Mohamed Rifaat Ahmed ${ }^{*}$ (D) and Wael Elshahat Eldeeb
}

\begin{abstract}
Background: Otitis media with effusion (OME) is one of the commonest causes of hearing loss in children. Oral and nasal topical steroids alone or combined with antibiotics lead to its quicker resolution. The aim of this study was the assessment of the efficacy of mometasone furoate nasal spray in conjunction with oral antibiotics for management of OME in children. One hundred sixty-eight children aged (4-12 years old) diagnosed with bilateral OME for at least 3 months were randomly allocated into two equal groups: the 1st group received mometasone furoate aqueous nasal spray plus oral amoxicillin-clavulanate for 4 weeks, and the 2 nd group received amoxicillin-clavulanate alone for the same period.

Results: The tympanometric results after 1 month of medical treatment was much better in the 1st group compared to the 2 nd group with $60 \%$ of patients of the 1 st group having type A tympanogram versus $16 \%$ of patients of the 2nd group having this type $(p=0.0001)$. However, the average air-bone gap was not statistically different between the two groups.
\end{abstract}

Conclusion: Mometasone furoate nasal spray is effective in OME as adjunctive treatment when combined with antibiotics as it helps to normalize the Eustachian tube function and middle ear status.

Keywords: Otitis media, Hearing loss, Topical steroid, Tympanometry, Mometasone, Effusion

\section{Background}

Otitis media with effusion (OME), which is defined as accumulation of non-purulent fluid behind the intact eardrum, is considered a major cause of conductive hearing loss in the pediatric population. By the age of 10 years, about $80 \%$ of children are affected at least temporarily. In the developed world, the point prevalence reaches $20 \%$ [1-5].

Symptoms usually involve hearing loss or aural fullness but typically do not involve pain or fever. Hearing loss is often mild and may be detected only with audiogram [2].

*Correspondence: m_rifaat@hotmail.com

Faculty of Medicine, Suez Canal University, Ismailia, Egypt
Although majority of cases of OME are transient, a proportion of children develop persistent symptoms that may affect hearing, education, language, or behavior [3].

Classically, Eustachian tube dysfunction is cited as the main cause of OME. Physiologically, the Eustachian tube is responsible for pressure equilibration, clearance of secretions, and protection of the middle ear. Its dysfunction is attributed to its blockage either due to inflammation secondary to upper respiratory tract infection or allergies [4].

Daniel et al. concluded in their study that live bacteria are present in most middle ear effusions, strongly suggesting that bacteria and biofilms are also important in the etiopathogenesis of OME [5].

Management of OME is a matter of debate. Butler and van Der Voort reported that steroids and antibiotics separately or in combination lead to resolution of 
OME either by shrinking edema and tissues around the Eustachian tube, improving Eustachian tube surfactant secretion or by reducing the viscosity of middle ear effusion [6]. However, in 2008, the national institute of health and clinical excellence (NICE) recommended no antibiotics, no systemic or topical steroids, and no decongestant for management of OME [3].

Systemic steroids have severe side effects on the long term, and they provide only temporary improvement for short-term use. So, topical nasal steroids that are lacking these systemic side effects might be used alternatively in OME [7].

Mometasone furoate is a topical glucocorticosteroid nasal spray that can be used in children aged more than 2 years to manage the symptoms of allergic rhinitis including nasal blockage, rhinorrhea, itching, and sneezing [8]. In addition, it has a role in symptomatic improvement in children with adenoid hypertrophy [9].

The aim of this study was assessment of the efficacy of mometasone furoate as a topical nasal steroid spray in conjunction with antibiotics for management of OME in children.

\section{Methods}

This randomized controlled clinical trial conducted in the Otolaryngology Department, Suez Canal University Hospital (Ismailia, Egypt), from October 2018 to September 2021. The study protocol was approved by the local ethics committee, and written informed consent was obtained from all patient caregivers.

One hundred sixty eight children aged (4-12 years old) diagnosed clinically and with tympanometry as bilateral OME for at least 3 months were included in the study.

Children with grade 2 and grade 3 adenoid hypertrophy according to a classification done by Mary et al. in 2005 [10] and children with craniofacial abnormalities such as choanal atresia and cleft palate were excluded from the study. Children who have hypersensitivity to mometasone furoate aqueous nasal spray or amoxicillinclavulanate acid antibiotic were also excluded.

Complete head and neck examination were done for all patients. Clinical signs of OME included signs of tympanic membrane retraction, loss of luster of tympanic membrane, and air bubbles or fluid level in the middle ear [11].

Pure tone audiometry and tympanometry were done for all subjects before the commencement of medical treatment. Tympanometric curves were categorized into three types as follows:

$$
\begin{aligned}
& \text { Type } A=\text { normal curve } \\
& \text { Type } C=\text { negative pressure } \\
& \text { Type } B=\text { flat curve }[12]
\end{aligned}
$$

Grades of the adenoid size were assessed with 0 degree $3 \mathrm{~mm}$ endoscope [10]:

Grade 1: $<50 \%$ of choanal space was occupied by the adenoid tissue

Grade 2: 50-75\%.

Grade 3: >75\% choanal obstruction

Additionally, X-ray soft tissue lateral view image of the nasopharynx was done to all children.

\section{Randomization to treatment groups}

The subjects were randomly divided into two equal groups. A computer-generated table of random numbers was used for group assignment; if the last digit of the random number was from 0 to 4 , assignment was to the 1 st group (study group), and if the last digit was from 5 to 9 , assignment was to the 2nd group (control group).

The 1st group was treated by mometasone furoate aqueous nasal spray $100 \mathrm{mcg} /$ day $(50 \mathrm{mcg} / \mathrm{puff}) 2$ puffs per each nostril once daily for 1 month as well as amoxicillin-clavulanate $90 \mathrm{mg} / \mathrm{kg} /$ day for 4 weeks [5-12].

The 2nd group was treated by amoxicillin-clavulanate $90 \mathrm{mg} / \mathrm{kg} /$ day for 4 weeks.

Proper health education was provided to the parents for proper use of nasal spray, and the first dose was given in the clinic. Follow-up was done after 2 and 4 weeks clinically and by tympanometry and audiometry.

\section{Statistical analysis}

Data collected were processed using the SPSS version 15 (SPSS Inc., Chicago, IL, USA). Chi-square test and $t$-test were used for comparison of tympanometric data and air-bone gap respectively. Statistical significance was chosen at 0.05 .

\section{Ethics considerations}

The local ethics committee approved the study. Written consent was obtained from parents of all study participants.

\section{Results}

The mean age of the 1 st group was $4.28 \pm 1.74$, while the mean age in the 2 nd group was $5.91 \pm 1.62$. In the first group, $65 \%$ of patients had type B tympanogram (55 cases) and 35\% (29 cases) were type C. In the 2nd group, $60 \%$ (50 cases) were type B, while $40 \%$ (34 cases) were type $C$ without any significant statistical difference between the two groups (Table 1). Mean air-bone gap in the right ear was $15.1 \pm 7.2 \mathrm{~dB}$ in the 1 st group and $13.9 \pm 7.1 \mathrm{~dB}$ in the 2 nd group. The mean air-bone gap in the left ear was $18.4 \pm 6.9 \mathrm{~dB}$ in the 1 st group and 
Table 1 Distribution of tympanometry in both groups (pretreatment)

\begin{tabular}{|c|c|c|c|c|c|c|}
\hline \multirow[b]{2}{*}{ Tympanometry } & \multirow[b]{2}{*}{ Type C } & \multicolumn{2}{|c|}{$\begin{array}{l}\text { First group } \\
N=84\end{array}$} & \multicolumn{2}{|c|}{$\begin{array}{l}\text { Second group } \\
N=84\end{array}$} & \multirow{2}{*}{$\begin{array}{l}P \text {-value } \\
>0.05(\mathrm{NS})\end{array}$} \\
\hline & & 29 & $35 \%$ & 34 & $40 \%$ & \\
\hline & Type B & 55 & $65 \%$ & 50 & $60 \%$ & \\
\hline
\end{tabular}

Chi-square test: NS no statistically significant difference

$14.1 \pm 7.1 \mathrm{~dB}$ in the 2 nd group without any significant difference between both ears in the 1st and 2nd groups.

Tympanometric results after 2 weeks of treatment in the first group revealed that $45 \%$ of patients (38 subjects) had type A normal tympanogram, 20\% (17 subjects) had type $\mathrm{C}$, and $35 \%$ (29 subjects) had a type B tympanogram. In the second group, tympanometric results revealed that only $10 \%$ (8 subjects) had type A tympanogram, 20\% (17 subjects) type $C$ tympanogram, and the majority $70 \%$ (59 subjects) had type B tympanogram. The difference was statistically significant $(p=0.0001)$ (Table 2$)$.

After 1 month of medical treatment, the tympanometric results in the 1 st group showed that $60 \%$ (50 subjects) had tympanogram type A curve, $30 \%$ (26 subjects) with type $\mathrm{C}$ tympanogram, and only $10 \%$ (8 subjects) with type B tympanogram, while in the second group, right ear tympanometric results were as follows: only 16\% (13 subjects) had normal type A tympanogram, 41\% (35 subjects) type $C$ curve tympanogram, and $43 \%$ (36 subjects) with type B flat curve denoting still OM tympanogram.
The difference was statistically significant $(p=0.006)$ (Table 3).

Follow-up with pure tone audiometry after 1 month revealed that the mean of air-bone gap in right ear was $6.51 \pm 7.55 \mathrm{~dB}$ in the 1 st group and $8.57 \pm 7.11 \mathrm{~dB}$ in the 2nd group. The mean of air-bone gap in the left ear was $8.50 \pm 7.21 \mathrm{~dB}$ in 1 st group and $10.35 \pm 7.15 \mathrm{~dB}$ in 2 nd group without any significant difference between the two groups (Table 4).

\section{Discussion}

Otitis media with effusion (OME) is a multifactorial disease, and ET dysfunction has been implicated as a predisposing factor for this disease. Some studies implicated allergy in the pathogenesis of OME [13]. By The age of 10 years, $80 \%$ of all children are diagnosed with at least one episode of OME. It is mostly diagnosed by the age of 3 years [14].

Kazanas and Maw reported that OME may be present without any significant hearing loss. They found that

Table 2 Distribution of tympanometry results in both ears in both groups after 2 weeks of treatment

\begin{tabular}{|c|c|c|c|c|c|c|}
\hline \multirow[b]{2}{*}{ Tympanometry (Rt) } & \multirow[b]{2}{*}{ Type A } & \multicolumn{2}{|c|}{$\begin{array}{l}\text { First group } \\
N=84\end{array}$} & \multicolumn{2}{|c|}{$\begin{array}{l}\text { Second group } \\
N=84\end{array}$} & \multirow{2}{*}{$\begin{array}{c}\boldsymbol{P} \text {-value } \\
0.006^{*}\end{array}$} \\
\hline & & 38 & $45 \%$ & 8 & $10 \%$ & \\
\hline & Type C & 17 & $20 \%$ & 17 & $20 \%$ & \\
\hline & Type B & 29 & $35 \%$ & 59 & $70 \%$ & \\
\hline \multirow[t]{3}{*}{ Tympanometry (Lt) } & Type A & 34 & $40 \%$ & 2 & $2 \%$ & \\
\hline & Type C & 21 & $25 \%$ & 37 & $44 \%$ & \\
\hline & Type B & 29 & $35 \%$ & 45 & $54 \%$ & \\
\hline
\end{tabular}

Chi-square test: * statistically significant difference

Table 3 Distribution of tympanometry in both ears in both groups after 1 month

\begin{tabular}{|c|c|c|c|c|c|c|}
\hline \multirow[b]{2}{*}{ Tympanometry (Rt) } & \multirow[b]{2}{*}{ Type A } & \multicolumn{2}{|c|}{$\begin{array}{l}\text { First group } \\
N=84\end{array}$} & \multicolumn{2}{|c|}{$\begin{array}{l}\text { Second group } \\
N=84\end{array}$} & \multirow{2}{*}{$\begin{array}{c}P \text {-value } \\
0.0001^{*}\end{array}$} \\
\hline & & 50 & $60 \%$ & 13 & $16 \%$ & \\
\hline & Type C & 26 & $30 \%$ & 35 & $41 \%$ & \\
\hline & Type B & 8 & $10 \%$ & 36 & $43 \%$ & \\
\hline \multirow[t]{3}{*}{ Tympanometry (Lt) } & Type A & 42 & $50 \%$ & 4 & $5 \%$ & \\
\hline & Type C & 38 & $45 \%$ & 50 & $60 \%$ & \\
\hline & Type B & 4 & $5 \%$ & 29 & $35 \%$ & \\
\hline
\end{tabular}


Table 4 Distribution of the mean of air-bone gap in both groups pretreatment and after 1 month

\begin{tabular}{llllll}
\hline & \multicolumn{2}{l}{ Pretreatment } & & \multicolumn{2}{l}{ After 1 month } \\
\cline { 2 - 3 } \cline { 5 - 6 } \cline { 5 - 6 } & First group & $\begin{array}{l}\text { Second } \\
\text { group }\end{array}$ & & First group & $\begin{array}{l}\text { Second } \\
\text { group }\end{array}$ \\
\hline $\begin{array}{l}\text { Air-bone gap } \\
\text { in right ear } \\
\text { (mean } \pm \text { SD) }\end{array}$ & $15.1 \pm 7.1$ & $13.9 \pm 7.1$ & & $6.5 \pm 8.7 .6$ & $8.5 \pm 7.2$ \\
$\begin{array}{l}\text { Air-bone gap } \\
\text { in left ear } \\
\text { (mean } \pm \text { SD) } \\
p \text {-value }\end{array}$ & $18.4 \pm 6.9$ & $14.1 \pm 7.1$ & & $8.6 \pm 7.1$ & $10.4 \pm 7.2$ \\
\hline
\end{tabular}

Student $t$ test: $N S$ no statistically significant difference

positive predictive value of abnormal tympanogram for hearing loss of $25 \mathrm{~dB}$ or more ranged from 49 to $66.4 \%$; they also suggested that tympanometry may be used as a screening for OME in younger children for hearing impairment, without the need for a pure tone audiogram [15].

In 2014, Rahul and Arunabha studied the effects of topical intranasal mometasone furoate nasal spray in children aged 2-12 years with bilateral OME and adenoidal hypertrophy. After 6 months, the resolution of middle ear effusion in study group was significantly higher as compared control group ( $p$ value 0.0004). Also, there was a significant symptomatic improvement in the study group $(p<0.04)$. Quality of life was dramatically changed with mometasone nasal spray in comparison to the saline nasal spray ( $p$ value 0.0001 ) [16]. In our study, parent concern about the use of topical steroid for several months made us opt for short follow-up period and to include only patients with mild adenoid hypertrophy.

El-Anwar et al. (2015) carried out a comparative study on 60 patients with OME who were divided into three equal groups. The first group received mometasone furoate spray, one puff in each nostril daily, for 3 months; the second group received oral prednisolone, $5 \mathrm{mg}$ three times per day for the first 3 weeks; and the third group received nasal saline spray, one puff in each nostril daily for 3 months. Audiological evaluation and clinical examination were done before treatment, 3 and 6 months after medical treatment. Their results revealed a highly statistically significant difference between systemic and topical (nasal spray) steroid therapy compared to saline nasal spray $(p<0.001)$. On the other hand, the difference between systemic and topical steroid was not significant $(p>0.05)$ [13]. Due to insignificant difference between systemic and topical steroid, we preferred to use topical mometasone furoate in the present study to avoid the side effects of systemic steroids.
Our results was supported by Cengel S and Akyol in their prospective, controlled, randomized study of 122 children aged 3 to 15 years old with adenoid hypertrophy and OME [7]. In their study, intranasal mometasone furoate monohydrate $100 \mathrm{mcg} /$ day was used, and children were evaluated at 0 and 6 weeks. The result was a significant higher resolution of OME in the study group $(42.2 \%)$ than the control group $(14.5 \%)(p<0.001)$. Also, there was a significant adenoid size decrease in $67.2 \%$ of patients in the study group when evaluated by endoscopy in comparison to the control group $(p<0.001)$ [7].

Contrary to our results and the study done by El-Anwar et al and by Cengel S and Akyol, Williamson et al. (2009) concluded in their double blind randomized placebo controlled study on 217 patients that 3 months use of topical intranasal corticosteroids in 4-11 year old children seems to be not better than placebo in improving clearance of effusions of otitis media at 1,3 , and 9 months, or in improving symptom-related outcomes [17]. They recommended that watchful waiting in primary care will spontaneously clear the fluid from at least one of their ears by as soon as one month and thus considerably reduce their risk of disability [17]. Active monitoring was also recommended by other authors, until natural resolution occurs after 1 or 3 months of follow-up $[18,19]$.

We could explain this significant discrepancy between studies regarding intranasal steroid spray and antibiotics by differences in pharmacological interventions including steroid formulation, duration of steroid treatment, and concomitant antibiotic.

We do not recommend using topical steroids that have high systemic absorption rate. This may increase the side effect without significantly improving the resolution of OME. Tracy et al. used intranasal beclomethasone which is more potent than mometasone as an adjunct treatment for middle ear effusion. After 1 month, there was only $15-16 \%$ difference in tympanometry outcomes and little effect (8\%) on symptomatic outcomes [20]. Also, we do not recommend oral steroids alone or in combination with antibiotics for OME because they are only effective in short term but the recurrence of OME is common [21].

In our study, we used topical mometasone furoate. We found it effective when used in combination with antibiotics to clear the middle ear effusion. Short-term follow-up and small sample sizes are the limitation and disadvantage of our study.

\section{Conclusion}

Mometasone furoate nasal spray is effective in OME as adjunctive treatment when combined with antibiotics as it helps to normalize the Eustachian tube function and middle ear status. 


\section{Acknowledgements \\ None}

\section{Authors' contributions}

MR analyzed and interpreted the patient data, followed up the patients, and collected the patient's data, WE was a major contributor in writing the manuscript and analysis of the statistical sections. All authors read and approved the final manuscript.

\section{Funding}

None

\section{Availability of data and materials}

Not applicable

\section{Declarations}

Ethics approval and consent to participate

Local ethics committee (Faculty of Medicine Suez Canal University under the number 1427 date of approval_September 2020). Written informed consent was obtained from all patients' caregivers/parents.

\section{Consent for publication}

Written consent for the study publication was obtained from all patients' caregivers/parents.

\section{Competing interests}

The authors declare that they have no competing interests.

Received: 22 September 2021 Accepted: 12 February 2022

Published online: 23 February 2022

\section{References}

1. Mandel EM, Doyle WJ, Winther B, Alper CM (2008) The incidence, prevalence and burden of $\mathrm{OM}$ in unselected children aged 1-8 years followed by weekly otoscopy through the "common cold" season. Int. J. Pediatr. Otorhinolaryngol. 72:491-499

2. Hassmann E, Skotnicka B, Baczek M, Piszcz M (2004) Laser myringotomy in otitis media with effusion: long-term follow-up. Europe Arch Otorhinolaryngol 261(6):316-320

3. National Institute for Health and Clinical Excellence. Surgical management of otitis media with effusion. (2008)

4. Yilmaz T, Koçan EG, Besler HT, Yilmaz G, Gürsel B (2004) The role of oxidants and antioxidants in otitis media with effusion in children. Otolaryngol Head Neck Surg 131(6):797-803

5. Daniel M, Imtiaz-Umer S, Fergie N, Birchall JP, Bayston R (2012) Bacterial involvement in otitis media with effusion. Int J Pediatric Otorhinolaryngol 76(10):1416-1422

6. Butler CC, van Der Voort JH (2001) Steroids for otitis media with effusion: a systematic review. Arch Pediatric Adolescent Med. 155(6):641-647

7. Cengel S, Akyol MU (2006) The role of topical nasal steroids in the treatment of children with otitis media with effusion and/or adenoid hypertrophy. Int J Pediatric Otorhinolaryngol 70:639-645

8. Penagos M, Compalati E, Tarantini F, Baena-Cagnani CE, Passalacqua G, Canonica GW (2008) Efficacy of mometasone furoate nasal spray in the treatment of allergic rhinitis. Meta-analysis of randomized, double-blind, placebo-controlled, clinical trials. Allergy. 63(10):1280-1291

9. Chohan A, Lal A, Chohan K, Chakravarti A, Gomber S (2015) Systematic review and meta-analysis of randomized controlled trials on the role of Mometasone in adenoid hypertrophy in children. Int J Pediatr Otorhinolaryngol. 79(10):1599-1608

10. Mary K, Anjali L, John M, Arif A, Jeyaseelan L (2005) X-rays in the evaluation of adenoid hypertrophy: its role in the endoscopic era. J Indian Assoc Pediatr Surg 57:45-47

11. Golz A, Angel-Yeger B, Parush S (1998) Evaluation of balance disturbances in children with middle ear effusion. Int J Pediatric Otorhinolaryngol 43(1):21-26
12. Jerger J (1970) Clinical experience with impedance audiometry. Arch Otolaryngology 92:311-324

13. El-Anwar MW, Nofal AA-F, Khazbak AO, Sayed AEE, Hassan MR (2015) The efficacy of nasal steroids in treatment of otitis media with effusion: a comparative study. International. Arch Otorhinolaryngol 19(4):298-301

14. Robb PJ (2007) Otitis media with effusion. In: Graham JM, Scadding GK, Bull PD (eds) Pediatric ENT. Springer, Heidelberg, pp 413-420

15. Kazanas SG, Maw AR. (1994)Tympanometry, stapedius reflex and hearing impairment in children with otitis media with effusion. Acta Otolaryngol 114(4):410-4. https://doi.org/10.3109/00016489409126079

16. Rahul B, Arunabha C (2014) A double-blind randomized placebocontrolled trial of topical intranasal Mometasone furoate nasal spray in children of adenoidal hypertrophy with otitis media with effusion. Am J Otolaryngol 35(6):766-770

17. Williamson I, Benge S, Barton S, Petrou S, Letley L, Fasey N, Haggard M, Little P (2009) Topical intranasal corticosteroids in 4-11 year old children with persistent bilateral otitis media with effusion in primary care: double blind randomised placebo controlled trial. BMJ. 16(339):b4984

18. Williamson IG, Dunleavey J, Bain J, Robinson D (1994) The natural history of otitis media with effusion- a three year study of the incidence and prevalence of abnormal tympanograms in four south west infant and first schools. J Laryngol Otol. 108:930-934

19. Hogan SC, Stratford KJ, Moore DR (1997) Duration and recurrence of otitis media with effusion in children from birth to 3 years: prospective study using monthly otoscopy and tympanometry. BMJ. 314:350-353

20. Tracy JM, Demain JG, Hoffman KM, Goetz DW (1998) Intranasal beclomethasone as an adjunct to treatment of chronic middle ear effusion. Ann Allergy Asthma Immunol 80:198-206

21. Mandel EM, CasselBrant ML (2006) Recent development of otitis media with effusion. Drugs. 66:1565-1576

\section{Publisher's Note}

Springer Nature remains neutral with regard to jurisdictional claims in published maps and institutional affiliations.

\section{Submit your manuscript to a SpringerOpen ${ }^{\circ}$ journal and benefit from:}

- Convenient online submission

- Rigorous peer review

- Open access: articles freely available online

- High visibility within the field

- Retaining the copyright to your article

Submit your next manuscript at springeropen.com 